\title{
ESTUDO DE UMA METODOLOGIA DIRECIONADA À INICIAÇÃO DE PALHAÇOS E PALHAÇAS
}

\author{
Hudson Salustiano Silva ${ }^{1}$ \\ Ana Elvira Wuo ${ }^{2}$
}

\begin{abstract}
RESUMO
$\mathrm{O}$ artigo apresenta dados preliminares de um projeto de pesquisa realizado no PPGAC-UFU cujo objetivo é investigar uma metodologia de apoio para o formador numa proposta de iniciação de palhaços e palhaças. Os dados discutidos neste trabalho foram obtidos do relatório de campo do primeiro encontro da investigação, cujo intuito foi de aproximar os colaboradores da arte palhacesca por meio de procedimentos expressivos dirigidos à comicidade. A descrição e a reflexão acerca da experiência vivenciada foram subsidiadas pelas teorizações de Bergson, Wuo, Achcar, Bogart e Landau, Burnier e Ferracini.
\end{abstract}

PALAVRAS-CHAVE: Comicidade; Formação; Iniciação; Palhaço; Palhaça

\section{ESTUDIO DE UNA METODOLOGÍA DIRIGIDA A LA INICACIÓN DE PAYASOS Y PAYASAS}

\begin{abstract}
RESUMEN
El artículo presenta datos preliminares de um proyecto de busca ejecutado en el PPGAC-UFU, cuyo objetivo es investigar una metodologia de apoyo para el entrenador en uma proposta de iniciación de payasos y payasas. Los datos discutidos em este trabajo se obtuvieron del informe de campo de la primera reunión de investigación, cuyo propósito era acercar a los colaboradores al arte de payaso a través de procedimientos expressivos destinados a la comicidad. La descripción y la reflexión sobre la experiência vivida fueron apoyadas por las teorizaciones de Bergson, Wuo, Achcar, Bogart e Landau, Burnier e Ferracini.

PALABRAS-CLAVE: Comicidad; Formación; Iniciación; Payaso; Payasa
\end{abstract}

\footnotetext{
${ }_{1}^{1}$ Professor de Artes e ator. Mestrando do Programa de Pós-Graduação em Artes Cênicas da Universidade Federal de Uberlândia (PPGAC-UFU). Projeto em andamento. 2020. Linha de Pesquisa: "Estudos em Artes Cênicas: poéticas e linguagens da cena. Bolsista CAPES.

2 Orientadora .Professora Adjunta do Curso de Teatro do Instituto de Artes da Universidade Federal de Uberlândia ( 2014) -Doutora em Artes da Cena, programa de pósgraduação -Instituto de Artes da UNICAMP( 2016) Pós-doutorado em Linguística no IEL Instituto de Estudos da Linguagem - UNICAMP (2008- 2011). Pós- doutorado na Faculdade de Educação Física -UNICAMP(2019-2020). Grupo de Pesquisa GEAC-UFU e CIRCUS-UNICAMP.
} 


\title{
STUDY OF A METHODOLOGY INTENDED FOR INITIATION OF CLOWNS
}

\begin{abstract}
The article presents preliminary data from a research project realized at PPGAC-UFU whose objective is to investigate a support methodology for the former in a proposal to initiate clowns. The data discussed in this work was obtained from the field report of the first investigation meeting, which purpose was to bring collaborators closer to the clown art through expressive procedures aimed at comedy. The description and reflexion about the lived experience was supported by the theories of Bergson, Wuo, Achcar, Bogart and Landau, Burnier and Ferracini.
\end{abstract}

KEYWORDS: Comicality; Formation; Initiation; Clown

$$
* * *
$$

\section{Apresentação}

O presente artigo apresenta dados preliminares do projeto de pesquisa intitulado "A performatividade clownesca e a (des)formação do formador na criação de uma metodologia para iniciação à comicidade" no PPGAC da Universidade Federal de Uberlândia - MG - Brasil. O projeto foi desenvolvido em dois momentos, envolvendo o mesmo coletivo de artistas colaboradores. O primeiro deles consistiu em aplicar exercícios dirigidos a neófitos colaboradores que se submeteram a uma proposta de formação relacionada a iniciação palhacesca, a qual será relatada e discutida neste texto. Já a segunda, buscará a reflexão a partir de saídas de palhaços em diferentes ambientes públicos, como escola, universidade, rua, praça, asilo e shopping, a qual discutiremos em uma outra próxima publicação.

A proposta da escrita se resume em apresentar uma abordagem exploratória, de caráter preliminar e descritivo do caderno de campo, cujas pretensões se restringem ao compartilhamento de impressões iniciais acerca deste primeiro encontro, bem como ao respectivo diálogo teórico apoiado em obras de pensadores relacionados à palhaçaria e à comicidade como Henri Bergson, Ana Elvira Wuo, Ana Achcar, Luís Otávio Burnier e Renato Ferracini. 


\section{Primeiro encontro: Sobre expectativas, insegurança e circunstância}

Inicialmente, para que o projeto obtivesse qualitativamente uma abordagem diversificada, buscou-se uma maior pluralidade de profissionais a fim de compor o coletivo de colaboradores da pesquisa. O contato com os colaboradores foi realizado por Facebook e WhatsApp procurando, sobretudo, artistas e interessados em arte, membros e ex-membros da Liga Acadêmica de Humanização Sarakura (Projeto vinculado à Universidade Federal do Triângulo Mineiro (UFTM), cujo principal objetivo envolve a prática e a presença de palhaços em ambientes hospitalares). Dessa maneira, a intenção era que a diversidade de depoimentos e experiências pudesse contribuir para uma pesquisa igualmente mais rica. Os participantes ${ }^{3}$ desta primeira reunião foram Breno, Karen, Fernanda, Pâmela e Renato, embora, eu contasse, ao todo, com a participação de treze integrantes - tendo um deles justificado ausência neste encontro inicial.

Os encontros da primeira etapa foram agendados para todos os sábados, entre os períodos vespertino e noturno, durante os meses de maio, junho e julho. Os colaboradores deveriam chegar entre 16:00 e 16:30, assim, teriam pelo menos trinta minutos para necessidades individuais como alongamento, relaxamento, meditação, alimentar-se ou escovar os dentes, por exemplo. Às 17 horas, pontualmente, iniciaríamos a prática coletiva sob minha orientação.

Conforme chegavam, liam o termo de autorização de uso de imagem e voz. Eles deveriam verificar se estavam de acordo e, posteriormente, assinar. Faltando 10 minutos para as 17 horas, haviam chegado somente quatro participantes: Renato, Pâmela, Fernanda e Breno. Aos poucos, a empolgação e a ansiedade foram dando espaço para sentimentos de angústia e insegurança.

Os lençóis que haviam sido levados não foram suficientes para cobrir toda a parede de espelhos da sala. Durante a tentativa de cortar a fita adesiva com a boca, a pele que revestia o meu lábio inferior saiu quase toda. O estrago foi tão evidente que Pâmela, Fernanda e Renato ficaram

\footnotetext{
${ }^{3}$ Os nomes dos artistas colaboradores foram alterados para preservar suas identidades.
} 
assustados com a camada de sangue que parecia pintar-me o lábio. Os dois aparelhos de sons do espaço definitivamente "não queriam" funcionar. Enfim, tudo parecia jogar contra, tudo parecia dar errado: o forte ruído dos automóveis passando na rua, o pilar no meio da sala que poderia provocar algum acidente, o baixo número de participantes presentes em comparação ao dos que confirmaram. Felizmente, recebi uma mensagem de Karen, que integraria o coletivo, com poucos minutos de atraso.

No processo investigativo iniciado pelas práxis, não houve teorização preliminar para os colaboradores, deixando a reflexão a posteriori, conforme nos aponta Wuo (2016, p.87). As instruções preliminares à prática resumiram-se à recomendação para desfazer qualquer imagem preconcebida acerca da figura do palhaço. Nesse sentido, foi esclarecido que o clown é o encontro do indivíduo com seu ridículo, seu fracasso, suas fragilidades, ou seja, com suas características risíveis. O movimento que deveriam fazer era o de abertura para a experiência e não de se fechar a uma possível imagem pré-determinada.

Como medida preliminar, WUO (2016, p.105) alerta para que o aspirante a clown não se apegue a modelos preexistentes. Ele deve encontrar a comicidade em si próprio. Portanto, WUO (2016, p.98) sugere ao iniciador que oriente aos iniciados o afastamento de imagens preestabelecidas sobre clown, auxiliando-os a neutralizar a referência. Essa atitude incentivaria a busca de uma comicidade pessoal, única, idiossincrática. A compreensão do que é ser palhaço deve igualmente ser própria, não cedendo aos ideais de clown do iniciador ou iniciadora. Para WUO (2016, p.99), as descobertas envolvem uma forma particular de raciocinar e executar as ações.

Dos cinco integrantes presentes, três já haviam participado de alguns encontros do Workshop de Iniciação à Palhaçaria, ministrado pelo autor do artigo no ano passado, em 2018: Karen, Breno e Pâmela. Embora não tenham seguido adiante com a pesquisa, o universo cômico e alguns procedimentos abordados, não era totalmente desconhecido por eles. Após recomendar a desconstrução do que acreditavam ser um palhaço, foi 
solicitado aos colaboradores que se deitassem no chão.

\section{Procedimentos preambulares em práxis:}

- Aquecimento (percepção + imaginação ativa + espreguiçar ativo)

Após todos terem se deitado, foram orientados para que fechassem os olhos e buscassem a posição mais confortável possível. Ao som de uma música instrumental em volume baixo, a proposta foi de que ampliassem sua percepção ao observarem como seus corpos estavam organizados no chão; que partes entravam em contato com o solo e quais delas reagiam à temperatura do piso; e como estavam suas respirações. Os participantes foram orientados a prestar atenção na manifestação de alguma tensão ou dor corporal, se percebiam cansaço ou ansiedade, como estavam a pulsação e os batimentos cardíacos.

Essas questões acerca da autopercepção vão de encontro com as experiências vividas pelo autor enquanto aluno de Mônnica Emilio na UniverCidade (Centro Universitário da Cidade) e, posteriormente, na UCAM (Universidade Candido Mendes). A atriz, bailarina e professora tinha o hábito de iniciar as aulas de consciência corporal, solicitando que seus alunos se deitassem na sala de trabalho. Na sequência, sugeriu-se a percepção de alguns detalhes como os mencionados no parágrafo acima.

Para WUO (2016, p.110) "O aquecimento é o momento de tomarmos contato com as próprias sutilezas, preparando os espaços corpóreos para a iniciação de clown". A doutora sugere que o aquecimento se inicie no espaço do chão - o que dialoga em concordância com grande parte das experiências do autor desta pesquisa enquanto ator-pesquisador dentro do curso de bacharelado em Teatro. WUO (2016) alega que "Esse tipo de aquecimento não se baseia somente em exercícios físicos, mas na preparação da percepção espacial do corpo".

Com a devida orientação, os colaboradores permaneceram deitados, enquanto permaneciam exercitando suas capacidades auto perceptivas. $\mathrm{Na}$ sequência, foi sugerido um exercício de imaginação criativa em que eram ditadas imagens a serem construídas. Basicamente houve um relato de uma 
viagem aérea em que eles contemplavam o céu, dirigiam-se até uma das portas da aeronave e se atiravam com liberdade na imensidão do horizonte. Por fim foi realizada uma contagem regressiva de 10 até 0 para que aterrissassem em seus próprios corpos.

Em seguida, iniciou-se outra fase do exercício: cada um, no seu tempo, deveria despertar por meio da movimentação de uma pequena parte do corpo, que se expandiria para sua totalidade em um espreguiçar ativo, contínuo e ininterrupto. Não se trata de um espreguiçar de abandono do próprio corpo, ao contrário, o indivíduo deve se engajar em despertar e buscar reconhecer as possibilidades de relação do corpo com aquele local e com as pessoas ao redor, ou seja, reconhecer-se no aqui e agora.

Esta etapa do aquecimento dialoga diretamente com os ideais de Renato Ferracini, ator e pesquisador. Ele recomenda que os atores iniciem o processo "com um longo e generoso espreguiçar de toda a musculatura [...] começando pelo chão, passando pelo plano médio, pondo-se de pé. A partir daí, esse espreguiçar começa a ser dinamizado até que o ator esteja pronto, física e organicamente...”. Ferracini completa alegando esta ser apenas uma sugestão inicial, cabendo aos atores a descoberta de qual seria a melhor maneira de se preparar para outras etapas em sua performance. (FERRACINI 1998, p.122).

Os participantes foram orientados, a abrir os olhos pouco a pouco e intensificar o ato de espreguiçar, perpassando pelos diferentes níveis do espaço, conforme sugerido por Ferracini (1998, p. 122). Após alguns minutos, eles deveriam se deslocar pelo espaço tendo o verbo espreguiçar ainda em mente.

A partir da percepção de que muitos colaboradores permaneciam olhando "para dentro", imersos em si e indisponíveis para a expansão de seus sentidos, eles foram orientados quanto à necessidade de voltarem seus olhares para o exterior. Por essa razão, no decorrer do processo, foi necessário repetir algumas vezes falas como: "Toda a minha ação é voltada para o outro", "Olhem para o outro, percebam o espaço". Aparentemente, Fernanda e Renato eram os que tinham o maior costume de encerrarem sua 
percepção em si próprios. À medida em que eram orientados sobre a necessidade de manter seus olhares voltados para fora, buscando elementos exteriores, os colaboradores assim o faziam.

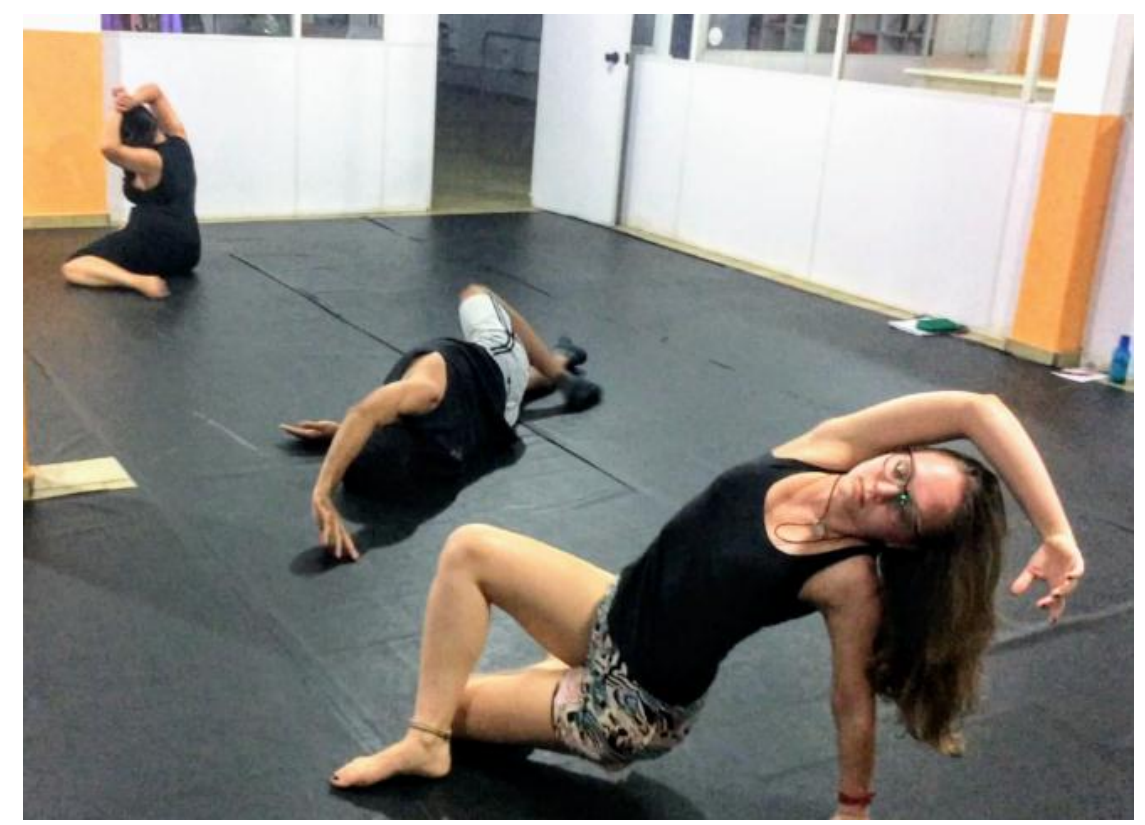

Figura 1 - Foto do arquivo de registro do autor

A pesquisadora e professora WUO (2016, p.113), em sua tese de doutorado, alerta para a necessidade de os neófitos voltarem sempre seu olhar para o espaço externo, mesmo durante os aquecimentos. Para ela, a relação deve ser estabelecida com o exterior, toda ação realizada deve ser para fora, para o outro - seja um colega, o espaço ou qualquer elemento cênico. A pesquisadora explica que essa regra deriva da "necessidade que o clown tem de estabelecer a relação com o público e, desde o primeiro instante, voltarmos nossa escuta do olhar para fora de nós mesmos, como um exercício de distanciamento do nosso próprio ego”.

\section{- Mini coreografia}

Após alterar as músicas instrumentais que tocavam para outra mais agitada - "Lacração", da cantora MC Loma - o ambiente "aparentemente" sério foi rompido e os colaboradores adquiriram um semblante mais leve. Seus corpos automaticamente adquiriram mais dinamismo, vida, flexibilidade e abertura de jogo. Pedi que cada um, ainda em deslocamento pelo espaço, por meio da investigação de movimento, criasse uma espécie de 
"dancinha" pessoal. Eles deveriam selecionar uma sequência de movimento que julgassem mais interessante, mantê-la e repeti-la como dança pessoal. Nesse ponto, já pareciam bem mais abertos a olhar para o outro, como um golfinho que decidiu sair das profundezas do mar para interagir com o exterior. Apesar da mudança considerável, era possível perceber ainda alguns momentos de olhares tímidos, interiorizados ou distraídos.

Depois de cada um definir seu movimento, foram posicionados em círculo e dançaram uns para os outros. Naquele momento era possível vê-los dançando e rindo de si próprios, da dança do outro, de toda a situação. Alguns movimentos eram definitivamente divertidos, desengonçados, descoordenados, exagerados. Após algum tempo, foi solicitado que reproduzissem a dança criada pelo colega posicionado à sua direita. A tarefa foi cumprida com alegria e disponibilidade. Era interessante vê-los se apropriar de uma coreografia completamente distinta da preestabelecida por eles. Era como ver uma criança vestindo as roupas dos pais - a sensação de estranhamento, devido a movimentação não se encaixar ao previamente conhecido, o que gerou um cenário de comicidade.

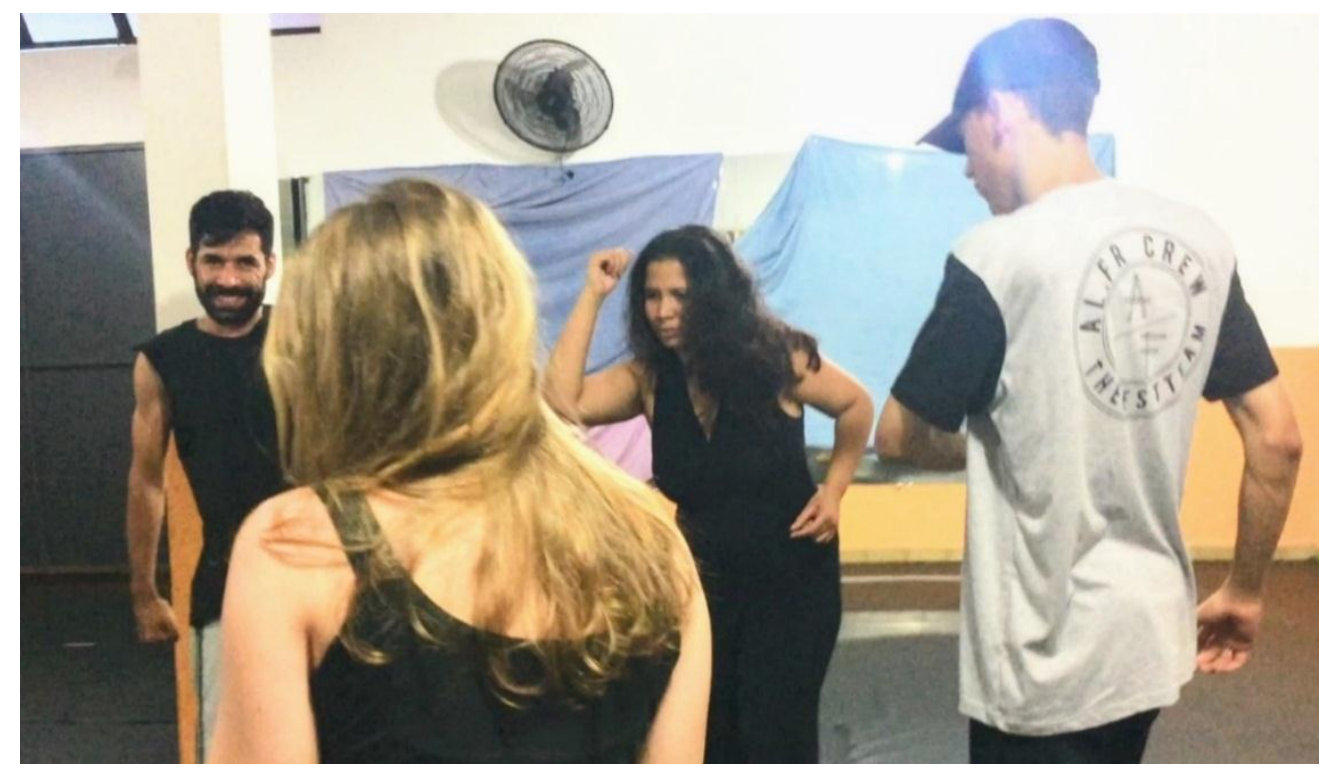

Figura 2 - Foto do arquivo de registro

Ana Lúcia Martins Soares (Ana Achcar), professora, atriz e pesquisadora brasileira, em sua tese de doutorado Palhaços de hospital: 
proposta metodológica de formação, tece o seguinte comentário acerca da figura do palhaço:

O palhaço faz rir explorando a exposição de suas limitações. A sua comicidade está expressa no exagero, na surpresa, na repetição das suas ações e atitudes, na revelação das suas características particulares e de seu modo de ser, na comunicação direta com o outro, na capacidade de assumir seu ridículo, seus erros e sua humanidade. (SOARES, 2007, P.112)

A exposição das características particulares dos artistas era evidenciada tanto na execução da dança pessoal inicialmente estabelecida pelo próprio executor, quanto na tentativa - desastrosa - de se apropriar da movimentação do outro. O fracasso estampado na cara dos participantes, tentando realizar outra coreografia de maneira bem-sucedida, despertoulhes gargalhadas.

Henri Bergson (1983), em seu livro "O Riso", faz uma abordagem, traçando uma possível interiorização do cômico. O tropeço, de acordo com ele, faz-se risível pelo desajeitamento, pela rigidez do sujeito diante da situação que lhe exigia competências de adaptação como desviar-se do obstáculo, por exemplo. De que maneira a comicidade se dá sem depender de um acaso, algum fato externo risível como tropeçar?

Para revelar a rigidez mecânica, será preciso não mais haver um obstáculo anteposto à pessoa pelo acaso das circunstâncias ou pela galhofa de alguém. Será preciso que venha do seu próprio fundo, por uma operação natural, o ensejo incessantemente renovado de se manifestar exteriormente. (BERGSON, Henri. 1983. P.9)

No caso dessa atividade, o obstáculo era a apropriação imediata da coreografia do outro. A ausência de flexibilidade para realizá-la de maneira competente. em tempo hábil, representou-lhes o trunfo de sua expressividade cômica. Em roda, sem a sensação de serem observados, sem sequer notar, iniciavam suas próprias caminhadas rumo à comicidade.

Para WUO (2006, p88), no que concerne a alguns procedimentos dirigidos à iniciação do clown, é importante o desenvolvimento de estratégias para que o aprendiz não se perceba observado, não se sinta analisado.

"O objetivo é que entremos num estado de soltura, sem preocupação com o resultado, desprendendo-nos de referências, e que penetremos no processo, o que assim nos permita aprender a desaprender, a errar, a duvidar, a questionar, a 
desformar e a formar o nosso conhecimento no nível da inversão do mesmo, transformando valores pessoais, sociais e culturais." (WUO, 2006, p.88)

Esse estado de soltura colabora para que os neófitos sintam-se à vontade para a exposição de suas características risíveis e, portanto, frágeis, patéticas, grotescas, inflexíveis, particulares, afinal. Seria bastante provável que os participantes "se armassem" caso se sentissem observados, seja fabricando uma falsa exposição dessas qualidades ou fechando-se diante do coletivo.

\section{- Fila da imitação}

Em uma segunda etapa foi solicitado que se organizassem em fila indiana. Eles deveriam imitar a pessoa à sua frente. Ou seja, de maneira geral, o primeiro da fila ditava a movimentação de todo o restante. Ao som de diferentes estilos musicais (ópera, instrumental, eletrônica e pop nacional) imitavam o "mestre" com entusiasmo. Cada estilo de som despertava um modo diferente de organizar sua expressão, sua movimentação corporal. A cada ordem para que trocassem de posição na fila, o mestre deveria se dirigir para o último lugar da fila, fazendo surgir um novo mestre: a pessoa que estava atrás dele.

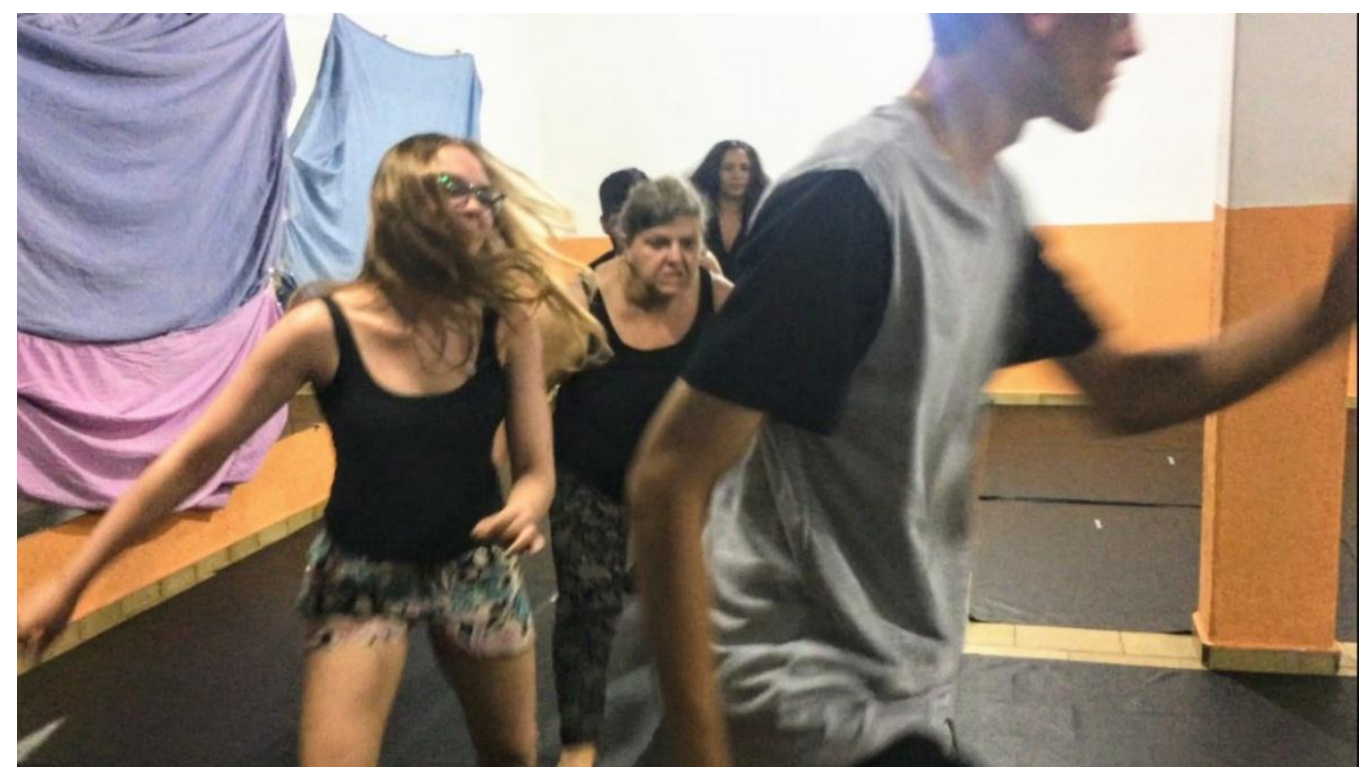

Figura 2 - Foto do arquivo do registro de autor 
$\mathrm{Na}$ tentativa de instruí-los a explorar possibilidades distintas do que demonstravam, eram feitas as seguintes sugestões: "Agora em câmera lenta!", "Agora o mais rápido que puder", "Agora eu quero que deixem os movimentos exagerados e amplos", "Agora eu quero movimentos pequenos, comedidos". Foi possível notar a dificuldade de alguns em romper com padrões de movimentação. As orientações, às vezes, demoravam para surtir um efeito estético na movimentação dos praticantes. Breno demonstrava dificuldade em executar dinâmicas de movimento muito lentas, por exemplo. Quanto mais estranha, subjetiva, inovadora, era a movimentação do mestre, maiores eram, automaticamente, o interesse e a empolgação dos outros que o seguiam. Era perfeitamente possível ouvir suas gargalhadas durante toda a prática desde que começamos com a dança pessoal.

\section{- Dança das cadeiras da morte}

Ainda em ritmo de alegria contagiante de dança, foi proposto um exercício da dança das cadeiras, com os puffs disponíveis no espaço. Aquele que ficasse de pé, sem cadeira, quando a música parasse, deveria morrer de uma maneira inusitada. Assim, o puff seria retirado e o jogo seguiria normalmente até que todos "morressem", inclusive o grande vencedor, que morreria logo após o penúltimo. As causas dos óbitos foram as mais diversas possíveis.

Dentre os episódios, o que mais chamou a atenção foi a morte de Renato com a participação de Karen. Ele parecia inicialmente sufocado; posteriormente, ficou claro que estava engasgado com algo. Então, Karen, com seu jeito nada sutil, abraçou-lhe por trás, apertando-lhe a barriga. Quando ela percebeu que não estava funcionando, começou a dar tapas nas costas de Renato que eram extremamente barulhentos. Os golpes foram se transformando em uma verdadeira pancadaria, culminando na morte de seu colega. O espaço foi tomado por muitas gargalhadas dos colegas. Naquele instante, pareciam tão livres da vaidade costumeira e exibicionista que tanto assola os atores. Suas feições demonstravam tanta alegria e plenitude. 


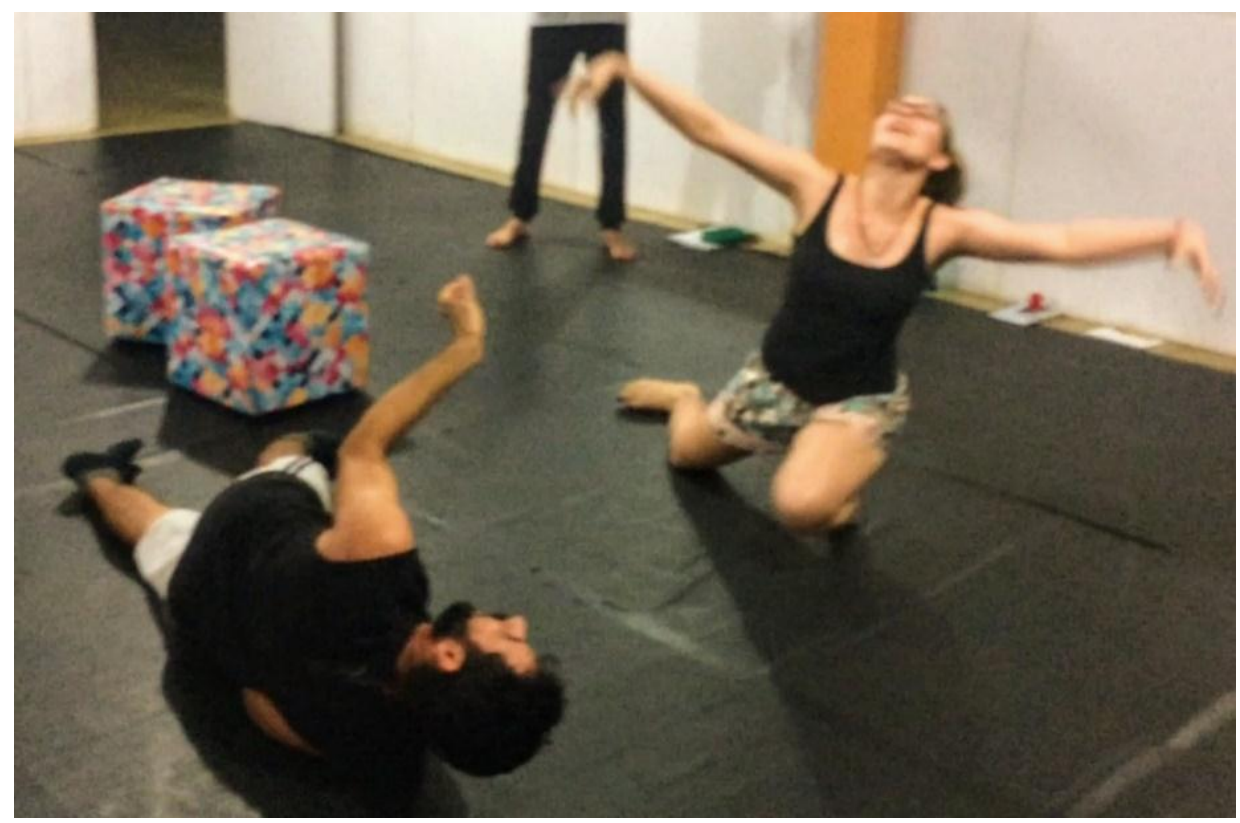

Figura 3 - Foto do arquivo do registro de autor

\section{Olhar com o nariz (ponto focal) ${ }^{4}$}

Após um curto intervalo, a atividade foi retomada com o exercício do "olhar com o nariz". Os colaboradores observaram atentamente a explicação verbal com auxílio de demonstração corporal. Parados em pontos distintos da sala, eles deveriam primeiramente buscar um foco em qualquer ponto do espaço. A imagem utilizada para fazê-los compreender, era a de que os olhos estavam na ponta de seus narizes. Em vez de buscar o ponto com os olhos, como seria feito de costume, deveriam utilizar a ponta de seus narizes, ou seja, a necessidade de "olhar com o nariz" faria com precisassem mover a cabeça e, consequentemente, o pescoço. Após fixar seu olhar no ponto escolhido, deveriam ajustar o restante do corpo, alinhando-o de acordo com a posição em que o pescoço estava. O objetivo deste jogo é trabalhar com a precisão do olhar com o nariz, preparando o ator para compreender a triangulação $0^{5}$. Ao olhar com o nariz, a plateia sabe exatamente onde a ação

\footnotetext{
${ }^{4}$ Procedimento vivenciado pelo pesquisador no segundo semestre do ano de 2013 no Curso de Bacharelado em Teatro do Centro Universitário da Cidade (Ipanema, Rio de Janeiro RJ). A prática foi realizada no módulo de Palhaçaria sob a orientação de Ana Luísa Cardoso (Margarita) - palhaça há mais de trinta anos. O nome e a descrição do exercício são de responsabilidade do autor.

${ }^{5}$ Segundo a autora é um sistema de jogo que inclui o espectador na cena como um terceiro foco (WUO, 2019).
} 
ocorre. Uma característica marcante do palhaço é a relação direta com o espectador, portanto, exercitar essa forma mais expandida de olhar é primordial para garantir precisão na performance clownesca. Nenhum dos cinco demonstrou dificuldade na execução dessa prática.

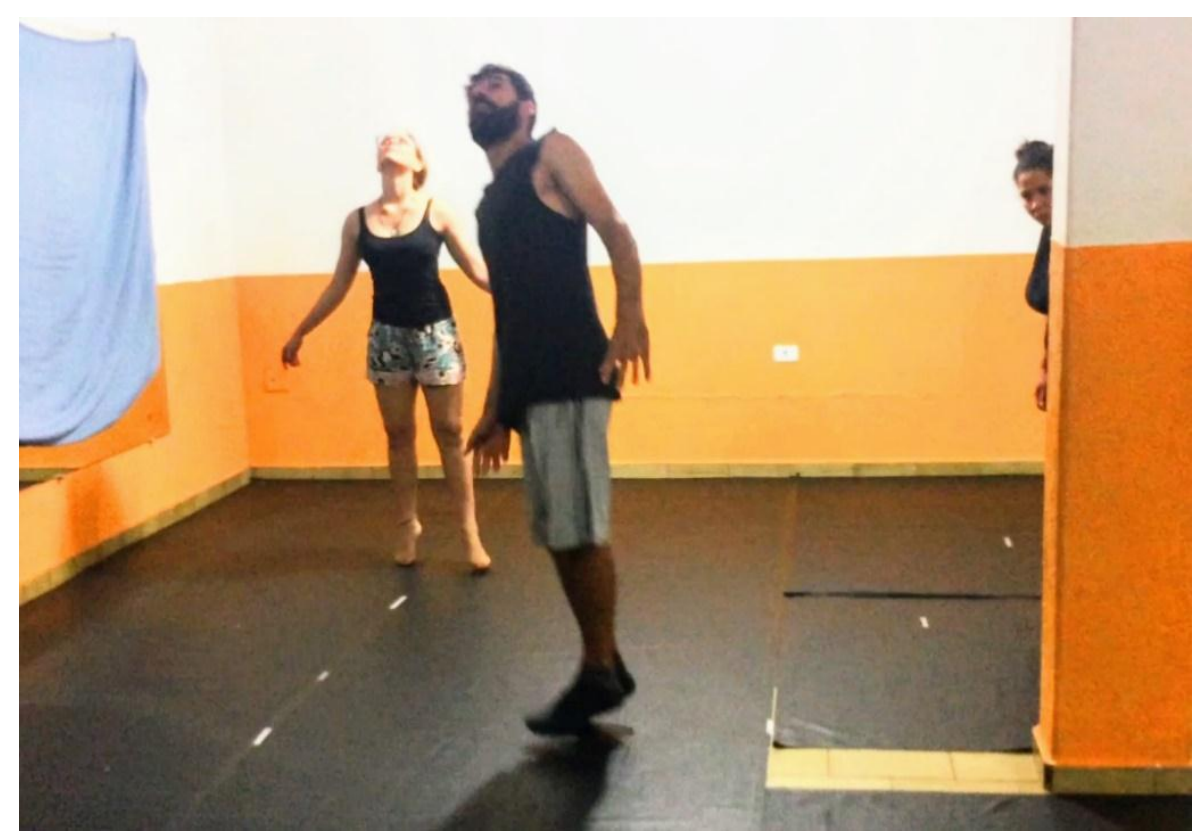

Figura 4 - Foto do arquivo do registro de autor

\section{- Olhar com o nariz (borboleta em espiral) ${ }^{6}$}

Para trabalhar outra dimensão do olhar com o nariz, foi também realizado o procedimento mencionado na tese de doutorado de Wuo. Embora o objetivo da prática permanecesse o mesmo, dessa vez seriam guiados por uma borboleta imaginária. Eles deveriam pensar em suas cores, formas e velocidade. Após bem estabelecida a imagem do inseto, segui-lo em movimentos espiralados. A maioria dos colaboradores demonstrou dificuldade maior para a realização desse exercício. Alguns, inclusive, perderam-se na movimentação de serem levados pelo nariz.

Tanto essa prática quanto a anterior exercitam o olhar: peça fundamental para a realização da triangulação. WUO (2016, p.120) alerta sobre a importância da noção do princípio da triangulação desde o primeiro instante de aprendizagem. A pesquisadora traz a comparação da técnica

${ }^{6}$ Procedimento sugerido na tese de doutorado "Clown: "desforma", rito de iniciação e passagem" (WUO, 2016, P.118). 
com um jogo em que os jogadores vão passando a bola um para o outro. Assim o faz o clown, frequentemente exibindo-se ou mostrando algo para o público, passando o foco de suas ações. Trata-se de uma estratégia para garantir a participação e a atenção do público no espetáculo. A cumplicidade do público está diretamente ligada ao olhar do palhaço, portanto, o devido gerenciamento de se exibir e passar o foco para outros elementos da cena deve ser um fator fortemente considerado na performance clownesca.

\section{- $\quad 1,2,3,4,5$ morto-vivo ${ }^{7}$}

Nesta nova dinâmica proposta, os colaboradores deveriam me considerar como o dono do circo. A crise financeira estava alarmante, e eles queriam muito um emprego no circo. Portanto, deveriam me impressionar e concordar com tudo que eu dissesse. Antes de prosseguir com mais explicações acerca da prática, todos deveriam dizer a primeira frase que viesse à cabeça. Em seguida foi questionado qual das frases mencionadas mais havia chamado a atenção do grupo. "Eu quero comer maçã", frase dita por Fernanda, foi a eleita.

Posteriormente, prosseguiu-se com as instruções: quando eu dissesse "Um!", eles deveriam caminhar pelo espaço; "Dois!”, correr; “Três!”, dizer a frase "Eu quero uma maçã”; “Quatro!", dar um salto; “Cinco!”, juntar-se em dupla ou trio. Os artistas deveriam dizer a frase escolhida de acordo com a maneira como fosse dita a palavra "Três", ou seja, se fosse dita cantando, deveriam cantar a frase, se fosse dita chorando, deveriam dizer a frase chorando. Outro detalhe é que somente poderiam se desfazer das duplas ou trio após escutarem "Cinco!" novamente. Enquanto não houvesse o comando, prosseguiriam com a prática em duplas ou trio: correriam, caminhariam e pulariam com o(s) parceiro(s).

Outro adicional remete ao clássico "morto e vivo". Ao comando de "Morto!", os colaboradores deveriam agachar, enquanto o comando "Vivo!", indicava a retomada da postura. Caso alguém se confundisse e executasse

\footnotetext{
${ }^{7} \mathrm{O}$ procedimento é uma livre adaptação de um exercício norteado por Kadu Garcia em diálogo com outro orientada por Ana Luisa Cardoso. As práticas foram realizadas no curso de bacharelado em Teatro do Centro Universitário da Cidade. As práxis foram reinventadas pelo autor do artigo, recebendo elementos adicionais.
} 
algo diferente do solicitado, eu chamava a atenção e mandava para o "cantinho da reflexão". O clima era de profundo engajamento na prática. A impressão era de que a complexidade e quantidade de códigos a serem obedecidos os desafiavam a corresponder com flexibilidade e competência e isso despertava-lhes prazer.

Os momentos em que alguém era advertido revelava reações diversas. Ao ser chamada a atenção, por exemplo, Pâmela abaixou a cabeça e contorceu as pernas, demonstrando vergonha. Isso ficava bastante evidente quando ela estava no cantinho da reflexão e me ouvir dizer "Aiaiai, que vergonha hein!": dava pequenos pulos contra a parede e contorcia ainda mais as pernas. Karen, por exemplo ficava irritada, fazendo "beicinho" e cruzando os braços com rebeldia. Breno esbugalhou os olhos e expressava-se com cara de desentendido. Renato expressava-se de maneira tímida e comedida, ingênua, transmitindo certa doçura. Cada um ali se expressou de maneira muito particular. Fernanda observava tudo com profundo interesse, parecia querer ver "o circo pegar fogo". Ela foi a única que conseguiu se safar e não teve sua atenção chamada durante todo o procedimento.

No meio de toda a dinâmica de correspondência aos "códigos", solicitava ações inusitadas. Nesse encontro foi pedido que se transformassem em um eletrodoméstico, que realizassem movimentos dignos de um super-herói, que incorporassem algum animal e que performassem cozinhando como um campeão do Masterchef. Os colaboradores permaneciam ocupados executando códigos enquanto possível, até que as performances imprevisíveis fossem solicitadas. Assim, evitou-se que suas mentes lhes pregassem peças. Eles deveriam confiar no imediatismo da ação em si, na execução do que foi solicitado. Trata-se de confiar na descoberta do fazer, do aqui-agora em detrimento do eventual planejamento.

Quando executavam alguma dessas ações indicadas, os que chamavam mais a atenção eram convidados para ir à frente, enquanto os demais assistiam. A primeira demanda foi a de se transformarem em um eletrodoméstico. Karen e Pâmela foram convocadas para performar. Cada 
uma realizava movimentos distintos que lembravam algum tipo de máquina que eu não soube identificar. Pedi que Karen se apresentasse com seu nome de eletrodoméstico. Após titubear milésimos de segundos, ela disse "Liquidalena", despertando o riso entre os colegas. A orientação deu-se no sentido de que toda a ação fosse voltada para a plateia. Além disso, os colaboradores deveriam agradecer sempre que percebessem o riso de algum colega. Esse processo faz com que o artista tome consciência de todos os momentos risíveis e, consequentemente, dos elementos cômicos de sua performance.

Contagiado pelo espírito brincante da sala de pesquisa acabei soltando uma piadinha: "Liquidalena, fiquei sabendo que você veio diretamente de uma liquidação". Naquele momento percebi que aquela atmosfera de liberdade ia adquirindo cada vez mais força. Pâmela apresentou-se como "Bateratudo". Os movimentos de ambas, especialmente de Pâmela, eram muito intensos e sua partitura fazia com que seu pescoço se enrijecesse, voltando seu rosto para baixo. Houve reiteradas orientações para que executasse as ações olhando para a plateia.

As duas colaboradoras foram orientadas a realizar seus movimentos em câmera lenta, explicando os porquês e o que de fato acontecia. Se o movimento implicava movimentos rotatórios com os braços, por exemplo, elas deveriam justificar os mecanismos acionados no eletrodoméstico de acordo com aquela movimentação específica.

Posteriormente, as duas deveriam se fundir em um novo eletrodoméstico e comecei a partir de contagem regressiva. Alarmadas, elas se juntaram, organizando seus corpos para formar um novo equipamento. Sem combinar, deveriam dizer juntas o nome do eletrodoméstico criado. "Bateratudo!", elas disseram buscando conexão por leitura labial. Pedi, então, para ver o eletrodoméstico em ação. Com as mãos dadas, em uma posição nada cotidiana e os joelhos flexionados, elas tornaram visível o novo eletrodoméstico, fazendo-nos gargalhar.

Para a segunda demanda, deveriam emanar poderes dignos de um super-herói. Fernanda, Renato e Breno chamaram a atenção, então 
assumiram a frente. Fernanda apresentou-se como "a super loira". Sua movimentação basicamente se resumia a jogar os cabelos para trás de maneira sensual. Quando perguntada sobre seus poderes, ela respondeu: "Ter cabelos sedosos", despertando-nos o riso. Breno apresentou-se como o super barba preta. Seus movimentos implicavam a expansão dos braços de maneira sinuosa. Quando executou a ação em câmera lenta, ele alegou fazer sair glitter e purpurina. Já Renato apresentou-se como "O Super bonépreto". Ele se movimentava de maneira sensual e feminina. Sua movimentação possuía similaridades à de Fernanda, entretanto, para jogar os cabelos - imaginários - para trás, ele utilizava toda a coluna, dirigindo-a para baixo, subindo, posteriormente, de maneira sensual. Vê-lo realizar o movimento em câmera lenta era hilário. Ter a sedução capaz de paralisar "as inimigas" foi a explicação dada por ele quando questionado.

Para a terceira demanda, deveriam se transformar em animais. Breno, Karen e Fernanda assumiram a posição da frente. Fernanda realizava movimentos felinos e exibicionistas. Ela apresentou-se como "leão jubão", deixando sua voz mais grave. Ao vê-la explorar o lado masculino frágil e manso de um leão, o grupo riu de sua performance. Karen fazia movimentos de voo e apresentou-se como "borboletinha da cozinha", fazendonos cair em gargalhadas - não apenas pela referência à música infantil bastante conhecida, como também pela maneira infantil e manhosa como se apresentou. Breno fazia movimentos e sons exagerados de macaco e se apresentou apenas como "macaco", despertando riso pela literalidade em sua apresentação sem um nome específico.

Fernanda estava um pouco mais retraída e resistente para olhar diretamente à plateia. Foi necessário lembrá-la algumas vezes de estabelecer esse contato visual. Provavelmente, o fato de não estar de pé dificultou-lhe o contato direto com a plateia, afinal ela deveria fazer um esforço maior para olhar para cima, ao mesmo tempo em que realizava suas ações apoiadas pelo joelho e mãos. Após alguns alertas, ela conseguiu manter este contato e sua potencialidade cômica voltou a se manifestar. 
Como última demanda do exercício, os atores deveriam cozinhar como um campeão do "Masterchef". Renato, Pâmela e Breno foram chamados à frente. Renato realizava movimentos rápidos de corte com as mãos, enquanto Pâmela aparentemente usava uma frigideira imaginária e Breno manipulava alguns ingredientes não decifrados. Na sequência foram solicitados, um por um, a se apresentarem como campeões de Masterchef de determinado país.

Era engraçado vê-los tentar fazer um sotaque oriental. Breno franziu tanto a testa e, sem falar absolutamente nada, já despertava gargalhadas. Seus olhos pareciam, de certa forma, ter características asiáticas, devido à contração facial. Quanto a Pâmela, enquanto realizava sua movimentação em câmera lenta, explicou que gratinava "camalão e balatinhas" (camarão e baratinhas) na frigideira, fazendo-nos rir. Já Renato emitiu uma voz mais aguda, cuja sonoridade era destacada em alguns momentos, como um carro com o motor falhando. Era comum percebê-los rindo uns dos outros ou até de si próprios enquanto performavam. A variada gama de características cômicas expressadas pelos alunos, denunciava e expunha o quão ingênuos e patéticos conseguiam ser. Quanto mais expunham esse lado ingênuo, mais revelavam o que se pode denominar um "patetismo" paspalho e, em consequência disso, provocavam o riso no restante do grupo.

Para Burnier (2001. p.209): "O clown é a exposição do ridículo e das fraquezas de cada um". Segundo o autor clown não se trata de uma personagem pronta, "mas da ampliação e dilatação dos aspectos ingênuos, puros e humanos...". Ou seja, para ele, o clown diz respeito à ampliação de características peculiares e inerentes ao artista, tais como suas debilidades e ingenuidades.

Com relação a ampliação dessas características, observei que os alunos pareciam encontrar a comicidade em aspectos distintos, ora ampliando aspectos ingênuos ao transparecerem a não compreensão acerca de algo, assumindo suas debilidades, ora revelando sua inflexibilidade e a incapacidade de corresponder expectativas externas ou internas com 
competência. Pâmela, por exemplo, em destaque de diversas outras coisas, encontrava a comicidade no conteúdo sagaz de suas palavras, na maneira de enunciá-las; Renato, na sonoridade extra cotidiana da voz; e Breno, no exagero de suas expressões faciais e em seu estado visivelmente perdido. Ambos nos fizeram rir por outras razões, mas naquele momento cada um apegou-se a características performáticas pessoais específicas. Eles demonstravam gerenciá-las, engajados em sua manutenção conscientemente ou não.

\section{Análise preliminar}

A teoria de Wuo embasou a práxis como elemento norteador para a proposição de exercícios disparadores, desencadeando o processo de iniciação à comicidade. Por meio da mesma teorização, foi possível reafirmar convicções anteriores sobre como trabalhar de maneira coletiva e individual com os participantes. Pedagogicamente, pude me inspirar em sua metodologia, reinventando práticas desformadoras, inventadas ou bebendo e outras fontes convergentes, trazendo outras influências da minha vida acadêmica para a pesquisa.

Destaco que, neste primeiro encontro, recorri em memória aos ensinamentos de meus professores da graduação, os quais representaram verdadeiros guias pessoais, que me auxiliaram a desenvolver autoconhecimento, sobretudo na maneira como meu contato com os alunos, mediou e afetou minha percepção neste experimento. A partir de então, devido a este primeiro encontro do projeto, ter sido pedagogicamente falando, muito potente, sinto-me mais seguro a exercitar a empatia e a mediar a continuidade dos procedimentos dirigidos à expressividade cômica, guiando os colaboradores iniciantes na arte da palhaçaria, rumo à abertura de novas perspectivas e descobertas como preparação metodológica para segunda etapa do meu projeto de pesquisa em andamento.

Dentro das expectativas, esse primeiro encontro deveria ser sobretudo acolhedor, afinal, minha pesquisa não existiria sem colaboradores. Cabia-me deixá-los com uma sensação de prazer - ainda que para alguns a exposição de fragilidades poderia ser traumática. Meu papel, 
enquanto proponente e mediador, era o de buscar frequentemente maneiras de camuflar minhas intenções de registros, deixando os participantes, dentro das possibilidades, à vontade para exibirem suas singularidades e o quão patética e ridente é a vida - incluindo si próprios.

Devido a algumas dificuldades observadas pelos colaboradores, recorri durante o processo a teorização do trabalho das diretoras artísticas Bogart e Landau, em que pode intuir uma excelente abertura para o desenvolvimento de maior consciência corporal e uso de expressividades na relação do artista com o tempo e o espaço. Essa é uma dificuldade de muitos atores - aspectos abordados no próprio artigo, relatando alguns exercícios. Vislumbro um melhor aproveitamento da expressividade cômica, se aliada à amplitude de possibilidades, tanto no uso dos viewpoints físicos, quanto dos vocais - especialmente dos últimos - já que o primeiro encontro apontou maior dificuldade de acesso à comicidade por meio de recursos vocais - se comparados aos de natureza corporal.

Dentro das expectativas criadas para um primeiro encontro, notouse excelente fluidez na realização dos procedimentos. Algumas noções de comicidade corporal começaram a despontar nos participantes, como a lógica pessoal, a triangulação, a conscientização dos erros como potencial risível, a não construção de personagem, bem como atuar com maior agilidade nas respostas, confiando e jogando com o tempo presente, assumindo inclusive não ter as devidas respostas verbais ou corporais para tudo o que lhe for solicitado.

Os participantes revelaram modos de ser e fazer comicidade de distintas formas: Karen e Breno, por exemplo, abusaram do exagero em suas performances. Pâmela despertou-nos o riso pela doçura patética e pelo conteúdo verbal igualmente patético em seus momentos de improviso. Renato, em especial, apesar da timidez para falar, demonstrou excelente utilização do corpo para se expressar comicamente. Fernanda, igualmente, possui boas qualidades corporais e, o fato de se perder em alguns momentos como Breno fazia isso tão pateticamente quanto o colega: não acompanhar 
certas expectativas revalidou-se por diversas vezes como ótimo recurso cômico.

\section{Considerações}

A partir da noção de que o primeiro encontro é um momento muito importante para o contato com a comicidade pessoal, percebi que foi necessário o respeito à forma expressiva de cada um, além de incentivá-los a mergulharem em suas subjetividades. Preliminarmente, os participantes mostraram disponibilidade, portanto, carrego a sensação de assertividade em minha condução. Ressalta-se ainda a importância de leituras de trabalhos investigativos, relacionados à comicidade, para a obtenção de pistas criativas. Isso favoreceu a iniciação preambular de alguns aspectos físicos do clown de cada um.

No que diz respeito aos neófitos, constatou-se por relato dos mesmos que não fizeram leituras preliminares sobre teorização do universo palhacesco. Suas descobertas surgiram pela experiência própria, mas que a partir do contato com a técnica e o despertar do interesse por teorias, foram sugeridas leituras posteriores.

A iniciação é um momento delicado e decisivo, que pode traumatizar ou acolher; despertar insegurança ou desejo. A importância da iniciação é soberana para aqueles que se interessam pela arte do clown. Após dialogar com os alunos, tendo em vista que nenhum deles abandonou a pesquisa, acredito que minha condução seguiu parâmetros humanos, sensíveis e estimuladores dos anseios artísticos de quem optou por estar ali.

Enfim, o primeiro encontro revelou, com base no apoio teórico metodológico, que a condução da formação conseguiu sustentar e tecer convergências com o experimento, apresentando ao neófito possibilidades diversificadas com a comicidade, as quais propiciaram o surgimento das primeiras impressões e aparições corporais palhacescas, Em meio a esta proposta inicial, os participantes se entregaram à prática e experimentaram ridiculamente os seus corpos, riram de si mesmos e conseguiram, de certa forma, rir de aspectos ridículos inerentes a corporeidade cômica do outro. A emissão sonora das gargalhadas 
palhacescas, em vários momentos, revelou que as descobertas surgiram de um lugar inusitadamente agradável ou não, mas que possibilitou aos iniciados, em meio à desformação do formador, transgredirem a norma social estabelecida e rirem de si próprios junto com os outros colegas, na emanação de um riso coletivo.

$$
\text { *** }
$$

\section{REFERÊNCIAS}

BERGSON, H. O Riso: ensaio sobre a significação do cômico. Trad. Nathanael Caixeiro. Rio de Janeiro: Zahar, 1983.

BOGART, Anne; LANDAU, Tina. O livro dos viewpoints: um guia prático para viewpoints e composição; organização e tradução Sandra Meyer. $1^{\mathrm{a}} \mathrm{ed}$. São Paulo, SP: Perspectiva, 2017.

BURNIER, Luís Otávio. A arte de ator: da técnica à representação. $2^{\mathrm{a} e d .}$ Campinas, SP: Editora da Unicamp, 2009.

FERRACINI, Renato. A arte de não interpretar como poesia corpórea do ator. 1998. 271 f. +. Dissertação de mestrado - Campinas, SP: Universidade Estadual de Campinas, Instituto de Artes, 1998. Disponível em: http://repositorio.unicamp.br/bitstream/REPOSIP/284021/1/Ferracini Renato_M.pdf. Acesso em: 19 jul. 2019.

SOARES, Ana Lúcia Martins. Palhaço de hospital: proposta metodológica de formação. 2007. Tese de doutorado em Teatro. Centro de letras e artes. Universidade Federal do Estado Rio de Janeiro - UNIRIO. Rio de Janeiro, 2007. Disponível em: http://www.circonteudo.com.br/stories/documentos/ar ticle/3781/S\%20oares,_Ana_L\%C3\%BAcia_M.\%20-Ana\%20Achcar_Palha\% C3\%A7o_de_Hospital....pdf. Acesso em: 19 jul. 2019.

WUO, Ana Elvira. Aprendiz de clown: abordagem processológica para iniciação à comicidade. 1 ed. Jundiaí-SP, Paco Editorial, Jundiaí, 2019. 
Clown: "desforma", rito de iniciação e passagem. 2016. tese de doutorado em Artes da Cena - Campinas: Universidade Estadual de Campinas, 2016. Disponível em: http://taurus.unicamp.br/bitstream/REPO SIP/321826/1/Wuo_AnaElvira_D.pdf. Acesso em: 19 jul. 2019.

Recebido em agosto de 2020. Aprovado em setembro de 2020. Publicado em outubro de 2020. 